\title{
Heat Transfer Coefficient in a Shallow Fluidized Bed Heat Exchanger with a Continuous Flow of Solid Particles
}

\author{
Araí A. Bernárdez Pécora \\ and Maria Regina Parise \\ The State University of Campinas \\ Faculty of Mechanical Engineering \\ 13083-970 Campinas, SP. Brazil \\ arai@fem.unicamp.br
}

This work shows the experimental study of a continuous gas-solid fluidized bed with an immersed tube where cold water is heated by fluidized solid particles presenting inlet temperature from 450 to $700^{\circ} \mathrm{C}$. Experiments were carried out in order to verify the influence of solid particle flow rate and distance between baffles immersed in a shallow fluidized bed. The solid material was $254 \mu \mathrm{m}$ diameter silica sand particles, fluidized by air in a $0.90 \mathrm{~m}$ long and $0.15 \mathrm{~m}$ wide heat exchanger. The measurements were taken at steady state conditions for solid mass flow rate from 10 to $100 \mathrm{~kg} / \mathrm{h}$, in a heat exchanger with the presence of 5 or 8 baffles. Bed temperature measurements along the length of the heat exchanger were experimentally obtained and heat balances for differential control volumes of the heat exchanger were made in order to obtain the axial profile of the bed-totube heat transfer coefficient. The results showed that heat transfer coefficient increases with the solid particle mass flow rate and with the presence of baffles, suggesting that these are important factors to be considered in the design of such heat exchanger.

Keywords: Shallow fluidized bed, experimental work, heat exchanger, bed-to-tube heat transfer coefficient, heat recovery

\section{Introduction}

Fluidized beds are commonly used in chemical, biochemical and petrochemical industries in processes such as hydrocarbon cracking, drying of solids, combustion and gasification of coal and biomass, thermal treatment of metals, recovery of energy from gases and hot solid particles, synthesis reactions and coating of particles.

Gas-solid fluidized systems are characterized by temperature uniformity and high heat transfer coefficients, due to the intense mixture of the solid material by the presence of gas bubbles.

A shallow fluidized bed (SFB) is characterized by small bed height, usually around $0.10 \mathrm{~m}$, and small gas bubbles. Applications of shallow fluidized beds include drying and heating/cooling of solid particles, due to the advantageous small bed pressure drop associated with it. Many researchers have been studying heat transfer in fluidized beds seeking to understand of the phenomenon and the determination of parameters that influence the suspensionwall or bed-to-tube heat transfer coefficient.

Mathur and Saxena (1987) and Chung and Welty (1990) investigated the influence of the bed temperature, superficial gas velocity and particle diameter on the heat transfer process. They observed the increase of the bed-to-tube heat transfer coefficient with the increase of bed temperature and gas velocity, and with the decrease of particle diameter.

Khan and Turton (1992) studied the influence of angular position around the tube, superficial gas velocity, particle diameter and the type of solid material on the heat transfer inside a fluidized bed with an immersed tube. They observed the increase of the heat transfer coefficient with the increase of gas velocity and with the decrease of particle diameter. They obtained the largest bed-to-tube heat transfer coefficient at $90^{\circ}$ and $120^{\circ}$ positions in relation to the bottom of the tube.

Ndiaye, Barboza and Steinmertz (1996) also studied the variation of the bed-to-tube heat transfer coefficient with bed temperature, verifying that the heat transfer coefficient increases with bed temperature for all tested conditions.

All these experimental works are related to batch conditions where there is temperature uniformity inside the fluidized bed. Literature review shows little research on fluidized beds with a

Paper accepted June 2006. Technical Editor: Clóvis R. Maliska. continuous flow of solid particles along the heat exchanger length, in spite of their technological importance in a process such as heat recovery. The movement of the solid particles, which is induced by the rising bubbles and axial pressure gradient, may have a distinct pattern near the tube wall and the solid pattern affects the bed-totube heat transfer coefficient. A continuous solid flow was studied by Rodriguez (1998) and Rodriguez, Pécora and Bizzo (2002). Rodriguez (1998) studied the influence of the particle diameter and solid particle mass flow rate on the bed-to-tube heat transfer coefficient in a shallow fluidized bed heat exchanger (SFB heat exchanger) with five immersed tubes. The author verified that the heat transfer coefficient increases with the decrease of the particle diameter and with the increase of the solid particle mass flow rate. A decreasing heat transfer coefficient, from the solid inlet to the solid outlet position, was also observed.

Rodriguez, Pécora and Bizzo (2002) made experiments in order to verify the influence of the presence of baffles in an SFB heat exchanger. Their results showed that baffles affect the bed temperature profile and the bed-to-tube heat transfer coefficient.

The present experimental study intends to increase the solid particle mass flow rate range and the number of baffles shown in work by Rodriguez, Pécora and Bizzo (2002), in order to verify their influence on bed-to-tube heat transfer coefficient and temperature profiles along the heat exchanger length.

\section{Nomenclature}

$A=$ heat transfer area, $m^{2}$

$B=$ heat exchanger width, $m$

$c=$ specific heat at constant pressure, $J /(\mathrm{kg} \mathrm{K})$

$d_{p}=$ mean particle diameter, $m$

$d_{t}=$ external tube diameter, $m$

$d_{t,}=$ internal tube diameter, $m$

$H=$ heat exchanger height, $m$

$h_{b}=$ bed-to-tube heat transfer coefficient, $W /\left(m^{2} K\right)$

$h_{w}=$ water-tube convective heat transfer coefficient, $W /\left(m^{2} K\right)$

$k=$ thermal conductivity, $W /(m K)$

$L=$ heat exchanger length, $m$

$L_{f}=$ fluidized bed height, $m$

$L_{j}=$ height of the heat exchanger window, $m$

$L M T D=$ logarithmic mean temperature difference, ${ }^{\circ} \mathrm{C}$

$\dot{m}=$ mass flow rate, $\mathrm{kg} / \mathrm{h}$

$n_{\text {baffles }}=$ number of baffles in the heat exchanger, dimensionless 
$P r=$ Prandtl number for the water flow, dimensionless

$\dot{q}_{b}=$ heat transfer rate from fluidized bed to tube, $W$

$R e=$ Reynolds number for the water flow, dimensionless

$S=$ distance between baffles, $m$

$T=$ temperature, ${ }^{\circ} \mathrm{C}$

$t_{1-19}=$ tests 1 to 19

$U=$ overall heat transfer coefficient, $W /\left(m^{2} K\right)$

$u_{m f}=$ superficial gas velocity at minimum fluidization condition, $\mathrm{m} / \mathrm{s}$

$u_{o}=$ superficial gas velocity, $\mathrm{m} / \mathrm{s}$

\section{Greek Symbols}

$\Delta x=$ differential length in the axial direction, $\mathrm{m}$

$\rho=$ air density, $\mathrm{kg} / \mathrm{m}^{3}$

\section{Subscripts}

$a=$ relative to air

$b=$ relative to fluidized bed

$i=$ relative to inlet conditions

$o=$ relative to outlet conditions

$s=$ relative to solid particles

$t=$ relative to tube

$x=$ relative to coordinate in the axial direction

$w=$ relative to water

\section{Experimental Setup}

The experimental system is schematically shown in Fig. 1, consisting of three main components: a bin for the sand particles; a fluidized bed combustor where the solid particles were heated by injection of liquefied petroleum gas (LPG) as fuel; and a fluidized bed heat exchanger where solid particles were cooled by air and by water flowing inside an immersed tube in the bed. The solid material was silica sand particles presenting $2650 \mathrm{~kg} / \mathrm{m}^{3}$ and $254 \mu \mathrm{m}$ as density and mean Sauter particle diameter, respectively. A pneumatic valve was used to feed the combustion chamber. A conical feeding valve with internal cooling was used to feed the heat exchanger with hot solid particles from the combustion chamber. After the heat recovery process, the cold sand left the heat exchanger towards a solid reservoir.

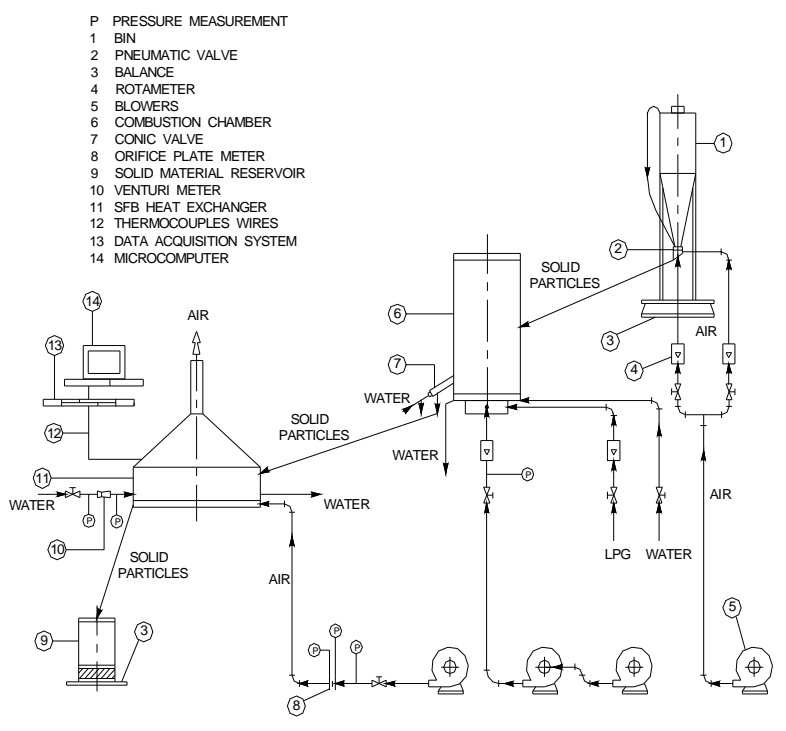

Figure 1. Experimental system.

The bed temperatures along the heat exchanger length and inside the combustion chamber were measured with type $K$ and $T$ thermocouples connected to a data acquisition system. Type $K$ thermocouples were immersed in the fluidized bed $0.02 \mathrm{~m}$ above the tube. It was assumed that the distance between tubes and thermocouples was large enough to assure that the measured values correspond to the bed temperature. The temperatures of the solid, air and water flows are also measured by thermocouples at the entrance and at the exit of the SFB heat exchanger. Pressure measurements were performed with a workbench of $U$ tubes connected to an orifice plate meter and a Venturi meter in order to measure air and water mass flow rates, respectively.

The heat exchanger with a shallow fluidized bed (Fig. 2) was made of carbon steel with one stainless steel tube, $0.0065 \mathrm{~m}$ external diameter, where the water flowed in a counter flow arrangement. The heat exchanger length $(L)$ was $0.90 \mathrm{~m}$ and the width $(B)$ was $0.15 m$, therefore the length-to-width ratio $(L / B)$ was equal to 6 . Such a ratio allows one to assume that there is a plug-flow for the solid material along the heat exchanger length. More information regarding the experimental setup can be found in Parise (2000).

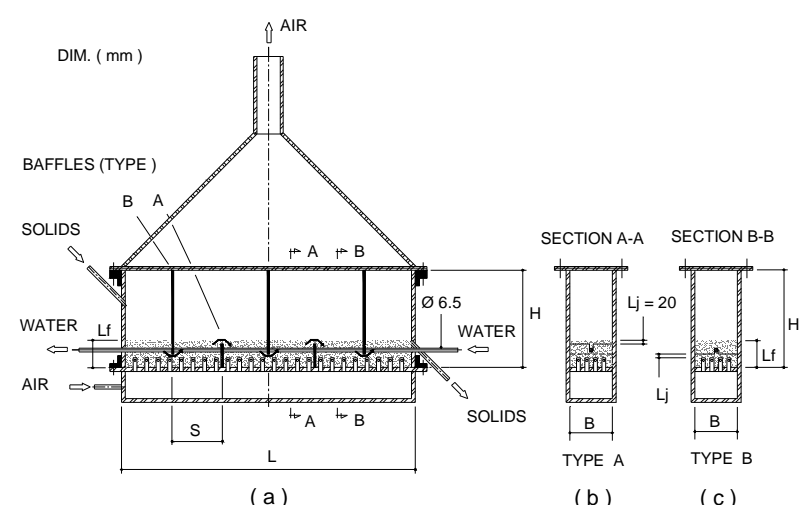

Figure 2. Heat exchanger with 5 baffles: (a) direction of solid material indicated by the arrows; (b) low baffle; (c) high baffle.

The first half of the experimental tests was performed with a heat exchanger without baffles $\left(n_{\text {baffles }}=0\right)$ and the second half was carried out with the presence of baffles. Configurations with five and eight baffles ( $n_{\text {baffles }}=5$ and 8 ) were tested, therefore distances between baffles $(S)$ of 0.15 and $0.10 \mathrm{~m}$ were used, respectively.

The experimental data were obtained when the system reached a steady state regime. All experimental tests were conducted with a constant bed height of $0.06 \mathrm{~m}$. The operational conditions in each experimental test are presented in Tab. 1 to 3 . These tables show the mass flow rates $(\dot{m})$, temperature $(T)$, superficial gas velocity $\left(u_{0}\right)$ and the ratio $\left(u_{o} / u_{m f}\right)$, where $u_{m f}$ is the superficial gas velocity at the minimum fluidization condition. The subscripts $i$ and $o$ refer to inlet and outlet conditions, respectively.

\section{Bed-to-Tube Heat Transfer Coefficient}

A methodology to obtain the bed-to-tube heat transfer coefficient along the heat exchanger length was developed from the experimental data. Energy balances were made in order to obtain the water temperature along the heat exchanger length $\left(T_{w, x}\right)$.

Supposing there is no heat loss for the environment, a vertically uniform bed temperature at $x$ position $\left(T_{b, x}\right)$ and plug flow for the solid material, the energy balance for a control volume of length $\Delta x$ (Fig. 3), provides Eq.(1):

$$
\dot{q}_{b, \Delta x}=\dot{m}_{b} c_{b}\left(T_{b, x}-T_{b, x+\Delta x}\right)=\dot{m}_{w} c_{w}\left(T_{w, x+\Delta x}-T_{w, x}\right)
$$


Heat Transfer Coefficient in a Shallow Fluidized Bed Heat Exchanger with a ...

Table 1. Operational conditions tested for the heat exchanger configuration without baffles $\left(n_{\text {baffles }}=0\right)$.

\begin{tabular}{|c|c|c|c|c|c|c|c|c|c|c|c|}
\hline \multicolumn{2}{|c|}{ Operational condition } & $t 1$ & $t 2$ & $t 3$ & 14 & $t 5$ & 16 & $t 7$ & $t 8$ & $t 9$ & $t 10$ \\
\hline \multirow{3}{*}{ Solid } & $\dot{m}_{s}[\mathrm{~kg} / \mathrm{h}]$ & 24.2 & 24.6 & 24.9 & 25.4 & 29.1 & 29.2 & 34.4 & 37.2 & 37.5 & 75.5 \\
\hline & $T_{s, i}\left[{ }^{\circ} C\right]$ & 510.5 & 526.0 & 490.0 & 722.5 & 664.0 & 544.0 & 597.0 & 621.0 & 611.0 & 627.0 \\
\hline & $T_{s, o}\left[{ }^{\circ} C\right]$ & 82.0 & 65.7 & 91.8 & 86.5 & 113.1 & 100.2 & 123.6 & 144.5 & 100.2 & 142.1 \\
\hline \multirow{3}{*}{ Air } & $\dot{m}_{a}[\mathrm{~kg} / \mathrm{h}]$ & 54.8 & 54.0 & 54.8 & 54.8 & 54.0 & 53.4 & 54.0 & 54.0 & 54.0 & 53.7 \\
\hline & $T_{a, i}\left[{ }^{\circ} C\right]$ & 38.8 & 39.7 & 42.9 & 42.1 & 46.9 & 47.3 & 46.2 & 49.0 & 46.0 & 51.3 \\
\hline & $T_{a, o}\left[{ }^{\circ} \mathrm{C}\right]$ & 154.0 & 147.0 & 163.0 & 210.0 & 201.0 & 210.0 & 213.0 & 249.0 & 195.0 & 225.0 \\
\hline \multirow{3}{*}{ Water } & $\dot{m}_{w}[k g / h]$ & 100.0 & 100.0 & 100.0 & 100.0 & 97.0 & 98.5 & 100.0 & 96.0 & 97.0 & 98.6 \\
\hline & $T_{w, i}\left[{ }^{\mathrm{o}} C\right]$ & 25.9 & 24.0 & 26.7 & 26.6 & 24.6 & 24.6 & 23.1 & 26.0 & 24.8 & 23.2 \\
\hline & $T_{w, o}\left[{ }^{\circ} \mathrm{C}\right]$ & 36.8 & 33.1 & 37.1 & 36.9 & 39.7 & 36.9 & 38.4 & 43.3 & 39.9 & 43.3 \\
\hline \multicolumn{2}{|c|}{$\bar{u}_{o}[\mathrm{~m} / \mathrm{s}]$} & 0.15 & 0.15 & 0.15 & 0.15 & 0.16 & 0.15 & 0.16 & 0.17 & 0.16 & 0.18 \\
\hline \multicolumn{2}{|c|}{$\bar{u}_{o} / u_{m f}$} & 3.8 & 3.8 & 3.9 & 3.9 & 4.0 & 3.9 & 4.1 & 4.5 & 4.2 & 4.5 \\
\hline
\end{tabular}

Table 2. Operational conditions tested for the heat exchanger configuration with five baffles $\left(n_{\text {baffles }}=5\right)$.

\begin{tabular}{|c|c|c|c|c|c|}
\hline \multicolumn{2}{|c|}{ Operational condition } & $t 11$ & $t 12$ & $t 13$ & $t 14$ \\
\hline \multirow[b]{2}{*}{ Solid } & $\dot{m}_{s}[k g / h]$ & 13.8 & 43.8 & 68.4 & 80.4 \\
\hline & $\begin{array}{l}T_{s, i}\left[{ }^{\mathrm{o}} \mathrm{C}\right] \\
T_{s, o}\left[{ }^{\mathrm{o}} \mathrm{C}\right]\end{array}$ & $\begin{array}{c}579.0 \\
87.6\end{array}$ & $\begin{array}{c}624.0 \\
86.1\end{array}$ & $\begin{array}{l}605.0 \\
294.2\end{array}$ & $\begin{array}{l}650.0 \\
313.1\end{array}$ \\
\hline \multirow[b]{2}{*}{ Air } & $\dot{m}_{a}[\mathrm{~kg} / \mathrm{h}]$ & 42.0 & 42.0 & 42.0 & 42.0 \\
\hline & $\begin{array}{l}T_{a, i}\left[{ }^{\mathrm{o}} C\right] \\
T_{a, o}\left[{ }^{\mathrm{o}} \mathrm{C}\right]\end{array}$ & $\begin{array}{c}37.4 \\
137.0 \\
\end{array}$ & $\begin{array}{c}34.3 \\
150.0 \\
\end{array}$ & $\begin{array}{c}46.3 \\
305.0 \\
\end{array}$ & $\begin{array}{c}43.5 \\
312.0 \\
\end{array}$ \\
\hline \multirow{3}{*}{ Water } & $\dot{m}_{w}[k g / h]$ & 93.9 & 93.9 & 93.2 & 93.2 \\
\hline & $T_{w, i}\left[{ }^{\circ} C\right]$ & 25.5 & 25.7 & 20.2 & 20.2 \\
\hline & $T_{w, o}\left[{ }^{o} C\right]$ & 41.8 & 46.0 & 68.3 & 71.6 \\
\hline \multicolumn{2}{|r|}{$\bar{u}_{o}[\mathrm{~m} / \mathrm{s}]$} & 0.13 & 0.14 & 0.17 & 0.18 \\
\hline \multicolumn{2}{|r|}{$\bar{u}_{o} / u_{m f}$} & 3.3 & 3.6 & 4.5 & 4.7 \\
\hline
\end{tabular}

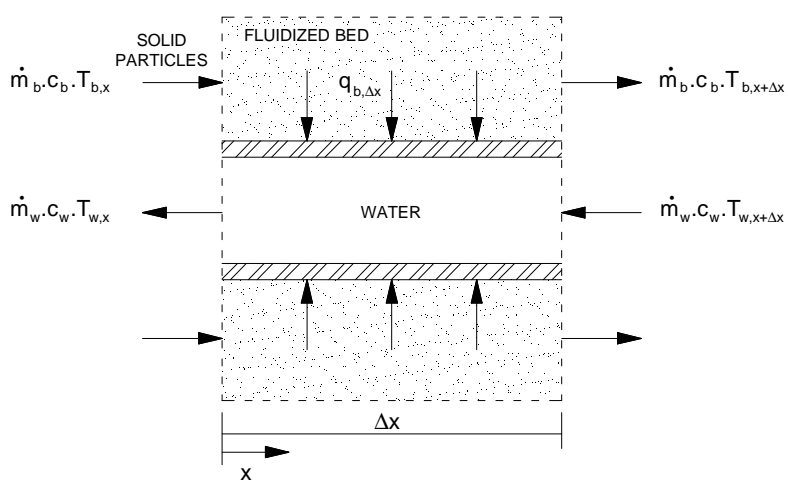

Figure 3. Heat balance for a control volume of length $\Delta x$.
Table 3. Operational conditions tested for the heat exchanger configuration with eight baffles $\left(n_{\text {baffles }}=8\right)$.

\begin{tabular}{|c|c|c|c|c|c|c|}
\hline \multicolumn{2}{|c|}{$\begin{array}{l}\text { Operational } \\
\text { condition }\end{array}$} & $t 15$ & t16 & $t 17$ & $t 18$ & $t 19$ \\
\hline \multirow{3}{*}{ Solid } & $\dot{m}_{s}[\mathrm{~kg} / \mathrm{h}]$ & 10.2 & 27.6 & 38.7 & 76.8 & 99.6 \\
\hline & $T_{s, i}\left[{ }^{\mathrm{o}} \mathrm{C}\right]$ & 562.0 & 632.0 & 650.0 & 707.0 & 708.0 \\
\hline & $T_{s, o}\left[{ }^{\circ} \mathrm{C}\right]$ & 66.8 & 82.8 & 96.7 & 234.9 & 214.3 \\
\hline \multirow{3}{*}{ Air } & $\dot{m}_{a}[\mathrm{~kg} / \mathrm{h}]$ & 42.0 & 42.0 & 42.0 & 42.0 & 42.0 \\
\hline & $T_{a, i}\left[{ }^{\mathrm{o}} C\right]$ & 41.6 & 38.4 & 36.2 & 34.6 & 31.9 \\
\hline & $T_{a, o}\left[{ }^{0} C\right]$ & 120.0 & 155.0 & 170.0 & 234.9 & 238.0 \\
\hline \multirow{3}{*}{ Water } & $\dot{m}_{w}[k g / h]$ & 93.5 & 93.5 & 93.5 & 92.3 & 92.3 \\
\hline & $T_{w, i}\left[{ }^{\circ} C\right]$ & 22.4 & 22.7 & 22.3 & 19.1 & 19.1 \\
\hline & $T_{w, o}\left[{ }^{\mathrm{o}} C\right]$ & 36.6 & 40.2 & 44.0 & 63.2 & 59.2 \\
\hline \multicolumn{2}{|c|}{$\bar{u}_{o}[\mathrm{~m} / \mathrm{s}]$} & 0.12 & 0.13 & 0.14 & 0.18 & 0.18 \\
\hline \multicolumn{2}{|c|}{$\bar{u}_{o} / u_{m f}$} & 2.9 & 3.5 & 3.7 & 4.5 & 4.6 \\
\hline
\end{tabular}

Where $\dot{q}_{b}, c_{b}, c_{w}$ are the heat transfer rates from the fluidized bed-to-tube and specific heat at constant pressure of the gas-solid fluidized bed and water, respectively.

The vertically uniform temperature can be adopted because almost instantaneous temperature equilibrium between gas and fine solid particles $\left(d_{p}<300 \mu m\right)$, as discussed by Molerus (1997). The plug flow for the solid material was adopted because of the lengthto-width ratio $(L / B=6)$ of the SFB heat exchanger. Such assumption was experimentally verified in previous works as Parise (2000) and Rodriguez (1998).

The bed heat flow $\left(\dot{q}_{b, \Delta x}\right)$ can be also given by:

$$
\dot{q}_{b, \Delta x}=U_{\Delta x}\left(\pi d_{t} \Delta x\right)(L M T D)_{\Delta x}
$$

Where $U_{\Delta x}, d_{t}, L M T D_{\Delta \mathrm{x}}$ are the overall heat transfer coefficient, external tube diameter and logarithmic mean temperature difference, respectively, for the control volume of length $\Delta x$.

Observe in Eq. (1) that $\dot{m}_{b} c_{b} \cong \dot{m}_{s} c_{s}$. Hypothesis commonly applied for gas-solid systems because $\rho_{s} \gg \rho_{g}$.

The energy balance showed in Eq. (1) provides a strategy to predict water temperature profile $\left(T_{w, x}\right)$, as $T_{b}$ is known along $x$. 
The average logarithmic mean temperature difference in the control volume of length $\Delta x$ can then be calculated as:

$$
\operatorname{LMTD}_{\Delta x}=\frac{\left(T_{b}-T_{w}\right)_{x}-\left(T_{b}-T_{w}\right)_{x+\Delta x}}{\ln \left[\frac{\left(T_{b}-T_{w}\right)_{x}}{\left(T_{b}-T_{w}\right)_{x+\Delta x}}\right]} .
$$

Therefore, the global heat transfer coefficient for each $\Delta x\left(U_{\Delta x}\right)$ can be obtained through Eq. (2) and (3).

Neglecting the fouling resistance, the bed-to-tube heat transfer coefficient at interval $\Delta x\left(h_{b, \Delta x}\right)$ is obtained from:

$$
\frac{1}{U_{\Delta x}}=\frac{1}{h_{b, \Delta x}}+\frac{1}{\bar{h}_{w, \Delta x}} \frac{d_{t}}{d_{t, i}}+\frac{d_{t}}{2 k_{t}} \ln \frac{d_{t}}{d_{t, i}}
$$

Where $\bar{h}_{b, \Delta x}, \bar{h}_{w, \Delta x}, d_{t, I}$ and $k_{t}$ are the bed-to-tube and water-totube heat transfer coefficients, internal tube diameter and thermal conductivity of the tube, respectively.

According to Incropera and DeWitt (1996), for turbulent flow in circular tubes, characterized by moderate property variations, the Dittus-Boelter equation is recommended. Considering the water properties at the mean temperature for each $\Delta x$, the water-to-tube heat transfer coefficient can be obtained by Eq. (5).

$$
\bar{h}_{w, \Delta x}=\frac{0.023 k_{w} \operatorname{Re}^{0.8} \operatorname{Pr}^{n}}{d_{t, i}}
$$

Where $n=0.4$ for heating and $k_{w}, R e$ and $P r$ are the water thermal conductivity, Reynolds and Prandtl numbers for the water flow, respectively. Equation (5) has been confirmed experimentally for the following range of conditions: $0.7 \leq P r \leq 160 ; R e \geq 10000$ and $L / d_{t, i} \geq 10$.

The methodology developed can be applied to gas-fine solid systems that involve heat exchanger between fluidized bed and immersed tubes. Such procedure makes possible predictions of the bed-to-tube heat transfer coefficient and it is useful to design fluidized bed heat exchangers.

The uncertainty analysis for gas-solid heat transfer coefficient was obtained by Eq. (6), as discussed by Holman (1994).

$$
\mu^{2}\left(h_{b}\right)=\sum_{i=1}^{N}\left(\frac{\partial h_{b}}{\partial y_{i}}\right)^{2} \mu^{2}\left(y_{i}\right)
$$

Where $\mu\left(y_{i}\right)$ represents the uncertainties of the measured temperatures and mass flow rates.

\section{Results and Discussion}

Experimental measurements of bed temperature as a function of the heat exchanger length $(x / L)$ are shown in Fig. 4 to 6

Figure 4 (tests without baffles) shows that the bed temperature along the heat exchanger follows an exponential tendency, but in Fig. 5 and 6 (tests with baffles), some regions present constant temperature, showing that there is bed temperature uniformity inside each region between two baffles.

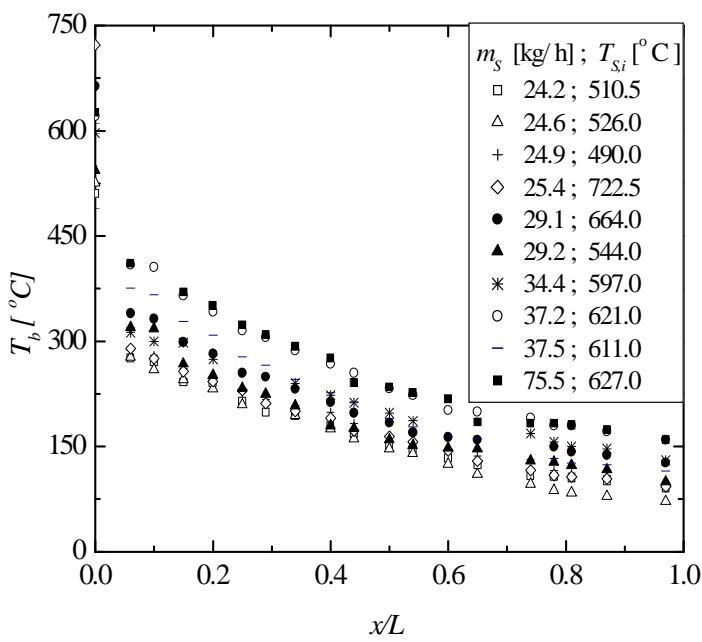

Figure 4. Bed temperature profiles for experiments without Baffles $\left(n_{\text {baftles }}=0\right)$.

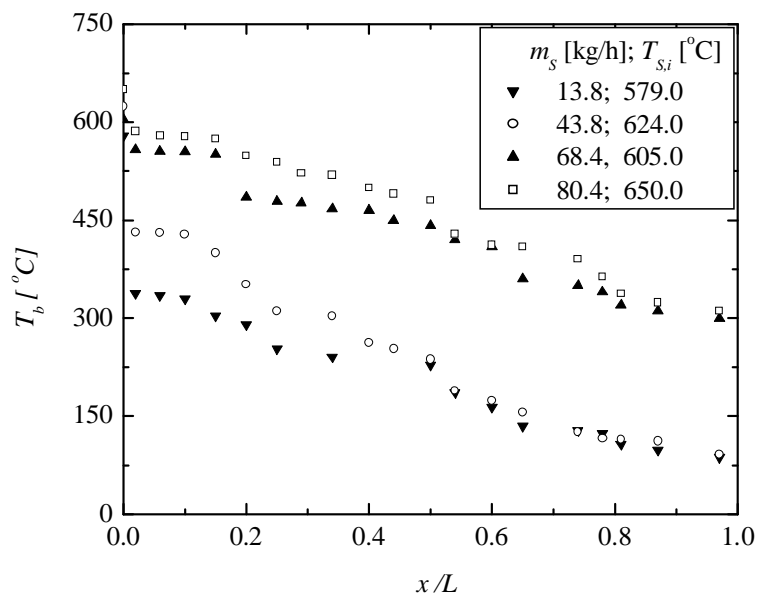

Figure 5. Bed temperature profiles for experiments with 5 baffles $\left(n_{\text {baffles }}=5\right)$.

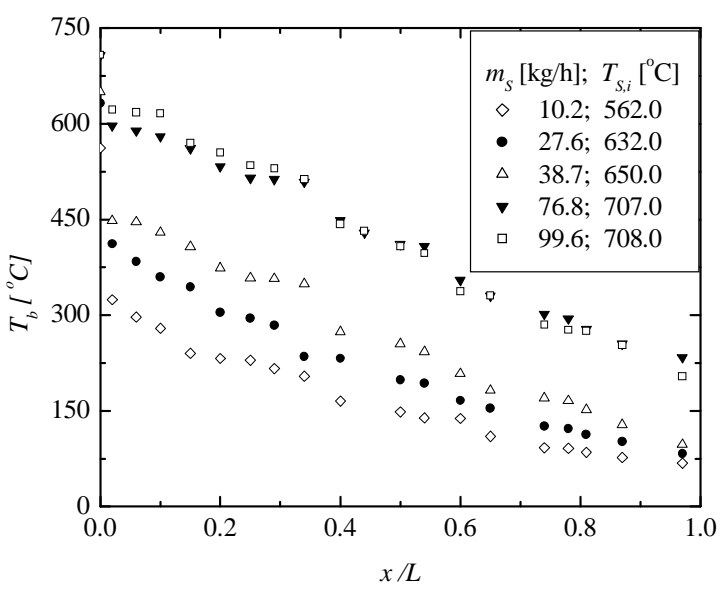

Figure 6. Bed temperature profiles for experiments with 8 baffles $\left(n_{\text {baftles }}=8\right)$. 
It was not possible to maintain a constant inlet solid temperature for all tests performed, because the cooling water flow rate inside the conical valve was constant. As the solid particle mass flow rate increased, the inlet solid particles temperature $\left(T_{s, i}\right)$ also increased, in spite of the bed temperature at the combustion chamber being approximately $850^{\circ} \mathrm{C}$ for all the tests.

Figure 7 shows a comparison of bed temperature profiles for the three heat exchanger configurations tested $\left(n_{\text {baffles }}=0,5\right.$ and 8$)$ for similar solid particle mass flow rates and inlet solid temperatures. A larger range of bed temperature variation was observed with the decrease of the distance between baffles, probably due to the longer residence time of solid material inside the heat exchanger, and to the increase of the bed-to-tube heat transfer coefficient.

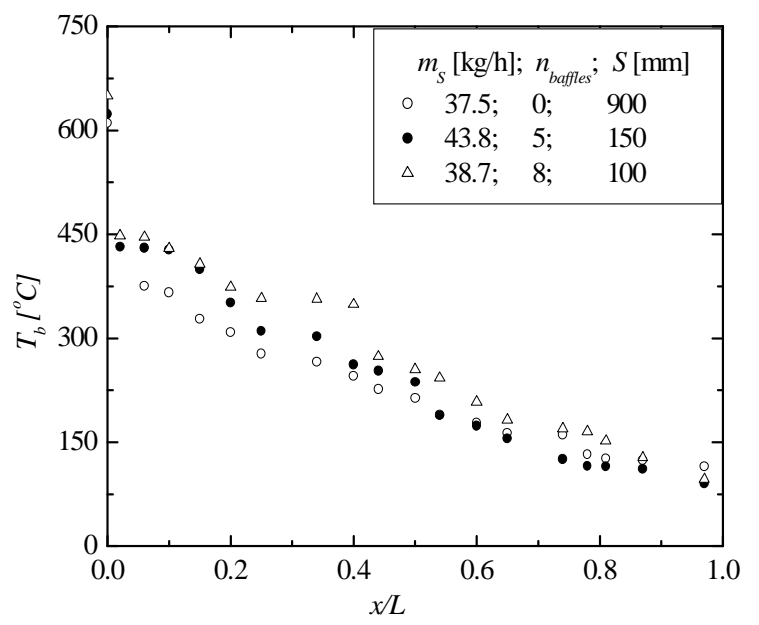

Figure 7. Influence of distance between baffles on the fluidized bed temperature profile.

Figures 8 to 10 show the profile of the bed-to-tube heat transfer coefficient $\left(h_{b}\right)$ for some tested conditions. It was verified that the heat transfer coefficient increases with the increase in the solid particle mass flow rate for all the heat exchanger configurations tested. Analyzing these figures, a decreasing profile for the heat transfer coefficient along the heat exchanger length, as reported previously by Rodriguez (1998), can be also verified.

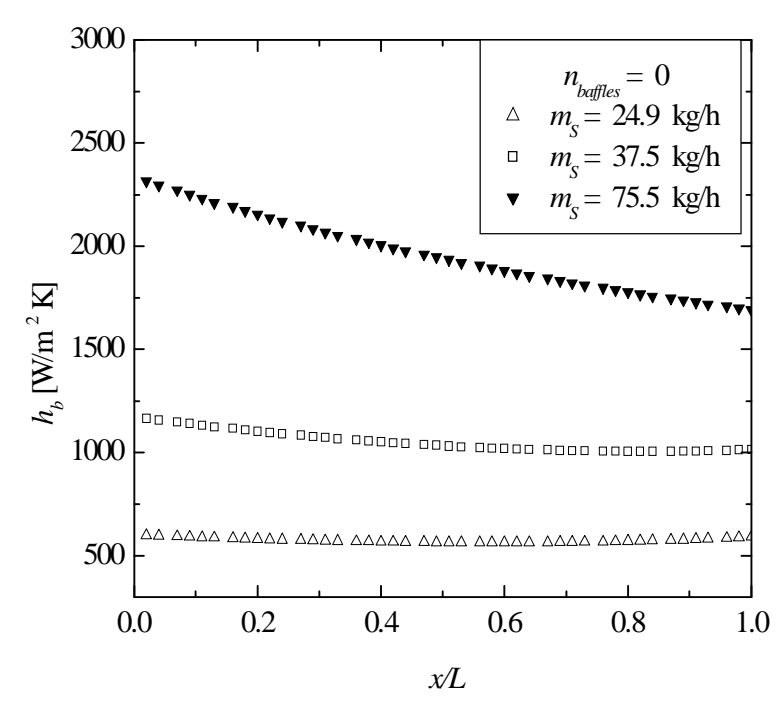

Figure 8. Bed-to-tube heat transfer coefficient profiles $-n_{\text {baffles }}=0$.

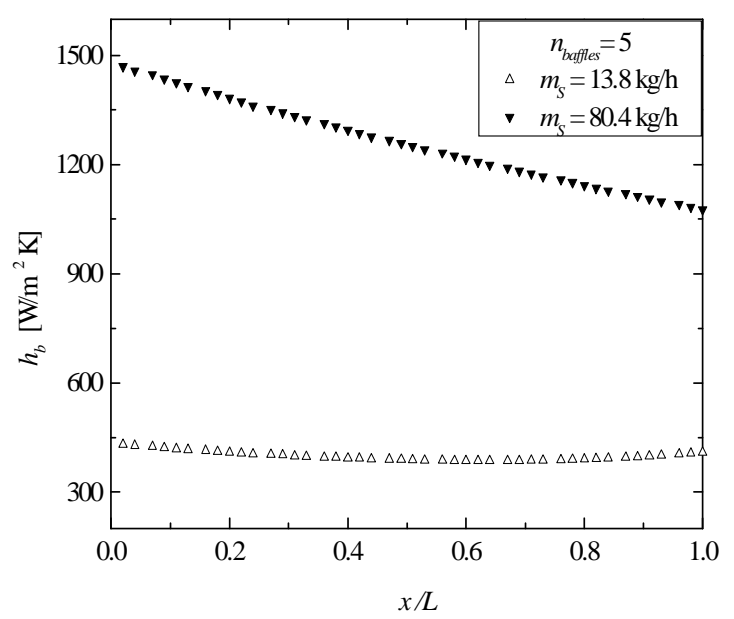

Figure 9. Bed-to-tube heat transfer coefficient profiles $-n_{\text {baffles }}=5$.

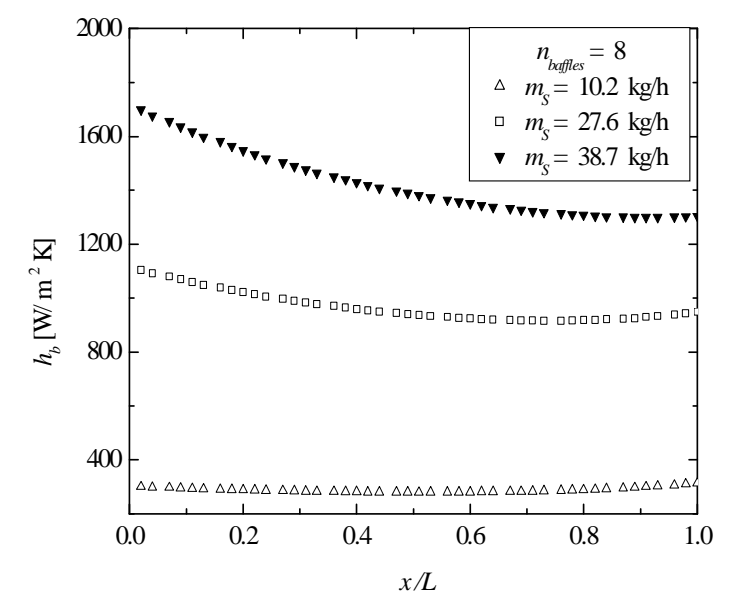

Figure 10. Bed-to-tube heat transfer coefficient profiles $-n_{\text {baffles }}=8$.

The influence of the number of baffles in the heat transfer coefficient can be seen in Fig. 11.

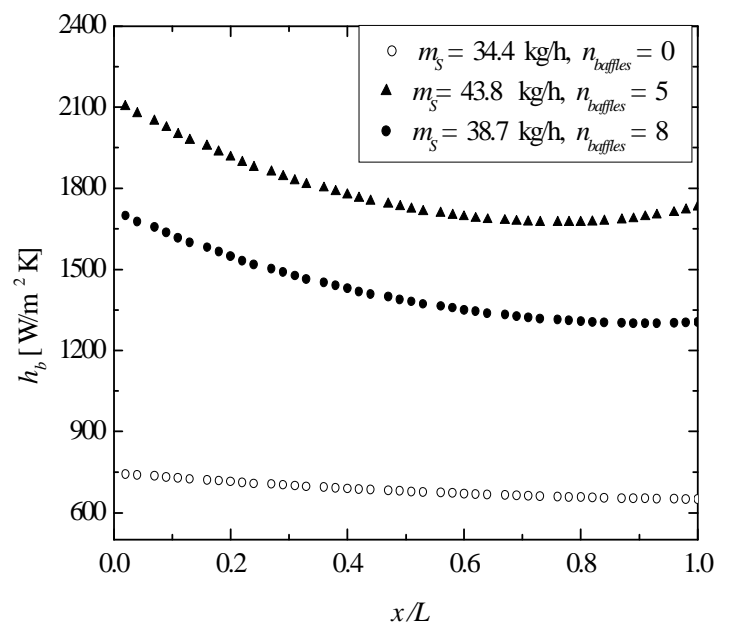

Figure 11. Bed-to-tube heat transfer coefficient profiles for the three heat exchanger configurations. 
It was noticed that larger heat transfer coefficients were observed when baffles were introduced in the heat exchanger, agreeing with the results found by Rodriguez, Pécora and Bizzo (2002). Such behavior is attributed to an increase in the horizontal component of the solid velocity with the presence of baffles. Higher heat transfer coefficients were obtained for the heat exchanger configuration with 5 baffles suggesting that distances between baffles around $0.15 \mathrm{~m}$ are recommended for the design of SFB heat exchangers. These results show that a more compact type of equipment can be designed when baffles are introduced in the fluidized bed, without any additional power requirement.

Experimental uncertainties for local heat transfer coefficient were in the range of 5 to $25 \%$. These values depend on the control volume location, because of the bed temperature profile along the heat exchanger length. Small temperature differences inside the control volume induce to high uncertainty degrees, therefore near the solid outlet position, the uncertainties are higher than near the solid inlet position.

\section{Conclusions}

This work contributes to fluidization engineering studies through experimental determination of bed temperature profiles and bed-to-tube heat transfer coefficient in shallow fluidized bed heat recovery equipment. Results showed that the heat transfer coefficient increases with the solid flow rate and with the presence of baffles inside the bed. Nevertheless, when the number of baffles increased from 5 to 8 , no significant changes were observed, suggesting that there is an optimum value for design proposes. Experimental results also showed that there is bed temperature uniformity between two adjacent baffles that is an important result mainly for reacting processes.

\section{Acknowledgments}

The authors wish to acknowledge FAPESP (Fundação de Amparo à Pesquisa do Estado de São Paulo), process 99/12784-7, for financially supporting this work.

\section{References}

Chung, T.Y. and Welty, J.R., 1990, "Heat Transfer Characteristics for Tubular Arrays in a High-Temperature Fluidized Bed: an Experimental Study of Bed Temperature Effects", Experimental Thermal and Fluid Science, Vol. 3, pp. 388-394.

Holman, J.P., 1994, "Experimental Methods for Engineers", McGrawHill international Editions, 616 p.

Incropera, F.P. and DeWitt, D.P., 1996, "Fundamentals of Heat and Mass Transfer", J. Wiley, 886p.

Khan, T. and Turton, R., 1992, "The Measurement of Instantaneous Heat Transfer Coefficients Around the Circumference of a Tube Immersed in a High Temperature Fluidized Bed", Int. J. Heat Mass Transfer, Vol. 35, pp. 3397-3406.

Marthur, A. and Saxena, S.C., 1987, "Total and Radiative Heat Transfer to Immersed Surface in a Gas-Fluidized Bed", AIChE Journal, Vol. 33, pp. 1124-1135.

Molerus, O., 1997, "Particle-to-Gas Heat Transfer in Particle Beds at Peclet Number Pe $\leq 10$ ", Powder Technology, Vol. 90, pp. 47-51.

Ndiaye, P.M., Barboza, A.L.S. and Steinmertz, D., 1996, "Efeito da Temperatura no Coeficiente de Transferência de Calor entre um Leito Fluidizado e Objetos Imersos", Proceeding of the Brazilian Congress of Particulate Systems, Uberlândia, Brazil, pp. 435- 440.

Parise, M.R., 2000, "Experimental Study of Solid Particle Cooling in a Fluidized Bed Heat Exchanger" (In Portuguese), MSc Dissertation, State University of Campinas, Campinas, SP, Brazil, 120p.

Rodriguez, O.M.H., 1998, "Heat Recovery Study from Particulate Solids using a Shallow Fluidized Bed" (In Portuguese), MSc Dissertation, State University of Campinas, Campinas, SP, Brazil, 153 p.

Rodriguez, O.M.H., Pécora and A.A.B., Bizzo, W.A., 2002, "Heat recovery from hot solid particles in a shallow fluidized bed", Applied Thermal Engineering, Vol. 22, pp.145-160. 